\title{
Hydraulic Characteristics and Numerical Simulation of the Entrance Section of Ladder-Shaped Spillway
}

\author{
X. B. Gu $\mathbb{D}^{1,2}$ Q. H. Wu $\mathbb{D}^{3}{ }^{3}$ Y. Wang, ${ }^{4}$ and H. X. Zhao $\mathbb{D}^{1}$ \\ ${ }^{1}$ School of Civil Engineering, Nanyang Institute of Technology, Nanyang, Henan 473004, China \\ ${ }^{2}$ Guizhou Provincial Key Laboratory of Rock and Soil Mechanics and Engineering Safety, Guiyang 550025, China \\ ${ }^{3}$ School of Architecture and Civil Engineering, Chengdu University, Chengdu, Sichuan, China \\ ${ }^{4}$ Hami Tuoshi Conservancy and Hydropower Survey and Design Limited Liability Company, Hami, Xinjiang 839000, China
}

Correspondence should be addressed to Q. H. Wu; 15700679755@139.com

Received 29 October 2021; Revised 29 November 2021; Accepted 7 December 2021; Published 28 December 2021

Academic Editor: Mohammed Fattah

Copyright (c) 2021 X. B. Gu et al. This is an open access article distributed under the Creative Commons Attribution License, which permits unrestricted use, distribution, and reproduction in any medium, provided the original work is properly cited.

\begin{abstract}
The ladder-shaped spillway in a certain reservoir junction is set as the engineering background in the paper. The hydraulic similarly model experiment and three-dimensional numerical simulation of hydraulic characteristics of water flow are performed. The outflow capacity, flow state analysis, velocity distribution, water surface line, pressure, and the energy dissipation rate are analyzed, and experimental results are compared with the numerical results. The conclusions demonstrate that the numerical results of the flow characteristics are very proximate to actual experimental results, the changeable law is the same, and their energy dissipation rate is basically consistent; it shows the feasibility of three-dimensional numerical simulation; the conclusions can provide the basis for the optimization about the flow state of the ladder-shaped spillway in the future.
\end{abstract}

\section{Introduction}

The ladder-shaped spillway is widely applied to the hydraulic engineering [1]. It has many virtues, for example, good energy dissipation efficiency, little engineering quantity, and low cost. The investigations on the water surface line, energy dissipation rate, aeration characteristic, the friction coefficient, and scale effect of model of the ladder-shaped spillway are gradually valued [2-4]. As deeper investigation is performed [5], it is realized that the macroscopical hydraulic parameters are connected [6] with the flow field structure of water. The investigation methods of flow field are developed from initial model experiment to the method in combination with model experiment and 3D numerical computation of turbulent flow [7]. The outflow capacity, water surface line, flow velocity distribution, etc. in Zhangfeng reservoir are simulated by $\mathrm{Li}$ et al. [8], and its results are consistent with the experimental ones [9]; the outflow capacity and water surface line of side-slot spillway are analyzed with comparison to verify the validity of hydraulic cal- culation by Yan et al. [10]; then, the energy dissipation of the ladder-shaped spillway is explored based on the flow velocity by Zhang et al. [11] and Shen et al. [12]. The influential factors of the ladder-shaped spillway are analyzed by Zhang et al. [13]; the physical model and numerical simulation are adopted by Knop and Mattioli [14] to analyze the hydraulic characteristic of the ladder-shaped spillway; the above investigations have enormously improved the development of the theory of hydraulic characteristics, and the numerical results can be verified by the experimental ones [15-17], so the numerical method with the experimental testing has been widely applied to model the flow state of water, especially for the spillway [18-20]. In the paper, the flow characteristic of the ladder-shaped spillway is simulated, and it is compared with the experimental results; the conclusions demonstrate that the method is feasible.

The paper is organized as follows: in section 2, the engineering background in the study area is introduced at first; in section 3, a hydraulic model experiment about the hydraulic characteristics is introduced; in section 4 , the numerical model 
about the hydraulic characteristics is performed; in section 5, the numerical results are compared with experimental results; in section 6 , conclusions are drawn.

\section{Engineering Background}

Certain reservoir is a multiyear regulating water-control project in a mountainous area; its type is small (1) in size. The engineering level is IV. The total reservoir capacity is $451 \times 10^{4} \mathrm{~m}^{3}$; its dead water level is $1896.22 \mathrm{~m}$, the normal storage water level is $1927.88 \mathrm{~m}$, the design flood level is $1929.02 \mathrm{~m}$, and the collated flood level is $1930.01 \mathrm{~m}$.

The ladder-shaped spillway is located at the right bank of the reservoir; it is a side channel spillway; WES practical weir is selected as the overflow weir. Initial regulating water level of the spillway is $1927.88 \mathrm{~m}$; the crest elevation of the weir is the same as one of the initial regulating water levels.

The total length of the spillway is $243 \mathrm{~m}$. It is composed of side weir section, adjustment section, ladder energy dissipation section, and stilling basin section. Water discharge under the collated flood level conditions $Q_{\max }=122.3 \mathrm{~m}^{3} / \mathrm{s}$. Water discharge under design flood level conditions $Q_{\max }=46.27 \mathrm{~m}^{3} / \mathrm{s}$. The section layout of spillway is plotted in Figure 1.

\section{Hydraulic Model Experiment}

3.1. Experimental Scheme. The calculative scope of the model is depicted as follows: the total length of spillway is $315 \mathrm{~m}$; the length of side weir section is $20 \mathrm{~m}$, one of the regulating sections is $15 \mathrm{~m}$, one of the ladder energy-dissipation sections is $190 \mathrm{~m}$, one of the stilling basin sections is $21 \mathrm{~m}$, and one of the tailrace channel sections is $69 \mathrm{~m}$; the similarity criterion of gravity is observed according to model design, and the normal model is adopted, the geometric scale of the model is $\lambda_{l}=25$; the similar scales of other hydraulic parameters are shown in Table 1 . The planar layout of the model is plotted in Figure 2. The full view of model is shown in Figure 3.

3.2. Fabrication and Installation of Materials. The selection of experimental materials must approximate to the roughness of actual materials to reflect the flow state of actual water in the spillway. According to the principle of gravity similarity [21], it can be expressed as follows:

$$
\lambda_{n}=\frac{n_{p}}{n_{m}}=\lambda_{l}^{1 / 6} .
$$

The roughness of actual discharge structure $n_{p}=0.015$, so the roughness of experimental discharge structure can be calculated as $n_{m}=n_{p} / \lambda_{l}^{1 / 6}=0.015 / 25^{1 / 6}=0.0088$. The range of roughness about plexiglass material is within 0.007 0.009 commonly, so the plexiglass is selected as the material of the spillway in the model [22].

The requirement of experimental installation is listed as follows: the layout of planar conducting wire is determined by the shape and scope of the model. The bearings of conducting wire are controlled by the theodolite, the permissive deviation is $\pm 0.1^{\circ}$, the elevation of model is controlled by the level, and the precise requirement should be satisfied $[23,24]$.

The requirement of experimental precision is shown as follows: the permissive error of elevation about the structure model is $\pm 0.3 \mathrm{~mm}$; the permissive error of the cardinal point of level and zero point of the probe is $\pm 0.3 \mathrm{~mm}$.

\subsection{Testing Method}

3.3.1. The Supply Facilities of Water. The water supply facilities of hydraulic model experiment are composed of cistern, power pump, level water tower, distributing pipe, backwater tank, etc.

3.3.2. The Experimental Measuring Instrument. The measuring instrument of water level and water surface line: water level gauge and steel gauge and level are adopted to measure the water level of constant flow. A manometer tube is selected as the monitoring of pressure.

The measuring instrument of flow velocity: a LGY-IIItype multifunctional intelligent current meter and pitot tube are adopted to monitor the flow velocity.

The measuring instrument of flow capacity: rectangular thin-walled weir is adopted to monitor the flow capacity of constant flow. The type of gauging weir should meet with the requirement of range and precision.

3.3.3. The Calculative Formula of Rectangular Thin-Walled Weir. It can be expressed as follows [25]:

$$
\begin{aligned}
Q & =m_{0} b \sqrt{2 g} H^{3 / 2}, \\
m_{0} & =\left(0.405+\frac{0.0027}{H}-0.03 \times \frac{B-b}{B}\right)\left[1+0.55\left(\frac{H}{H+p}\right)^{2}\left(\frac{b}{B}\right)^{2}\right],
\end{aligned}
$$

where $H$ is the water head of weir, $\mathrm{m}$; $P$ is the height of weir, $\mathrm{m}$; and $B$ is the width of weir, $\mathrm{m}$.

\section{The Numerical Simulation}

Flow3D simulation software is adopted to model the correlate experiments. The side weir section, regulating section, ladder energy dissipation section of discharge tank, stilling basin section, and tailrace channel section are included in calculative ranges; it is plotted in Figure 4. The prototype is adopted in the simulation. Initial inflow section is located at 20 meters ahead of the WES weir at the upstream of the model. The exit of the channel is located at the downstream of the model. The total length of the model is $315 \mathrm{~m}$; the boundary condition of the pressure inlet is adopted for water and gas inlet. The pressure all is atmospheric pressure at the boundary of the gas inlet. The boundary of the outlet is far from the side weir section, and the discharge tank is rather straight, so it has little influence on the turbulence in the side channel. Namely, the alteration of different physical quantities along the path tends to be constant. Nonslip boundary condition is adopted on the surface of wall. The method about the standard wall function is adopted to deal with a 


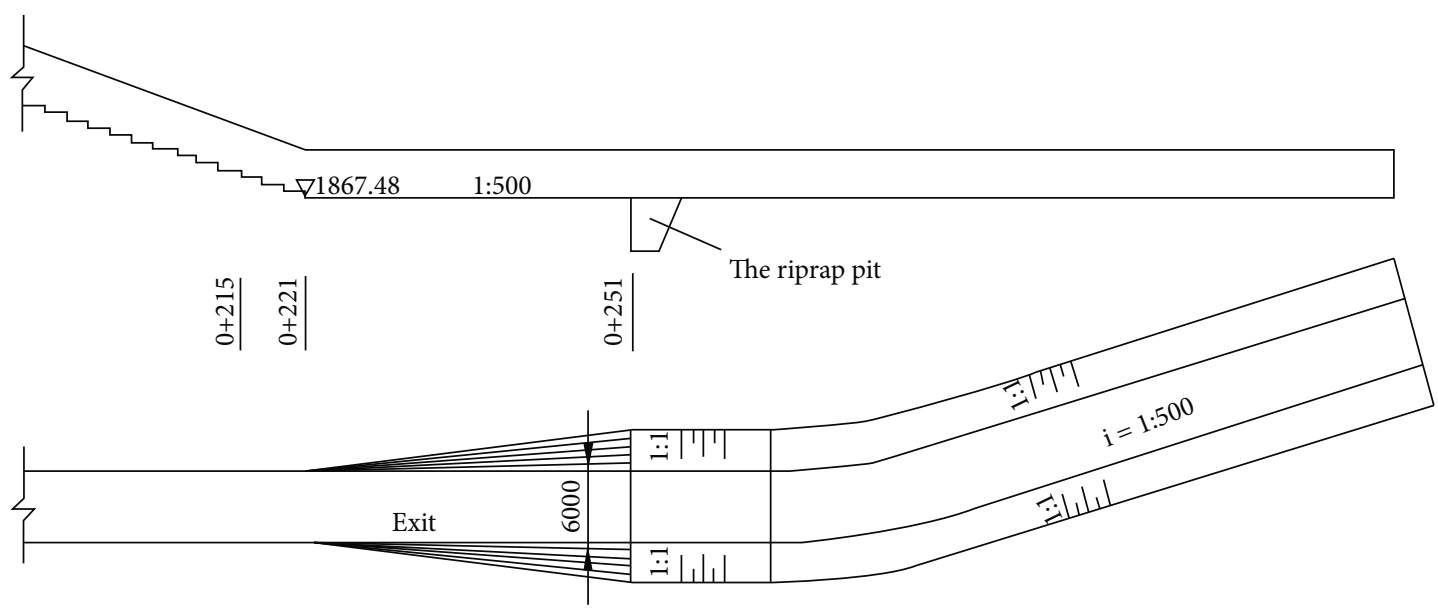

Figure 1: The section layout of spillway.

TABLE 1: Hydraulic parameter similarity under the condition of gravity similarity.

\begin{tabular}{|c|c|c|c|c|c|}
\hline Hydraulic parameters & Conversion relation & Similar scale & Hydraulic parameters & Conversion relation & Similar scale \\
\hline Length $l$ & $\lambda_{l}$ & 25 & Flow $Q$ & $\lambda_{Q}=\lambda_{l}^{5 / 2}$ & 3025 \\
\hline Pressure $p$ & $\lambda_{p / \gamma}=\lambda_{l}$ & 20 & Time $t$ & $\lambda_{t}=\lambda_{l}^{1 / 2}$ & 5 \\
\hline Flow velocity $v$ & $\lambda_{v}=\lambda_{l}^{1 / 2}$ & 5 & Roughness $n$ & $\lambda_{n}=\lambda_{l}^{1 / 6}$ & 1.60998 \\
\hline
\end{tabular}

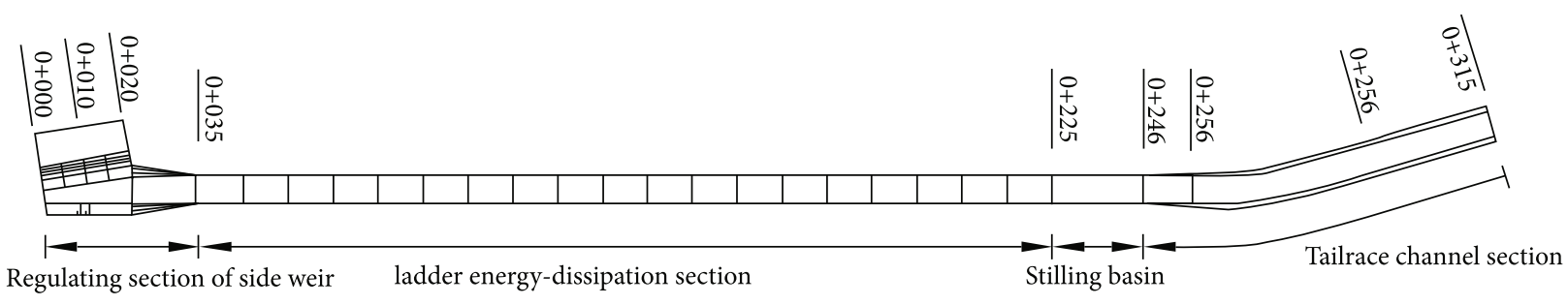

Figure 2: The planar layout of model.

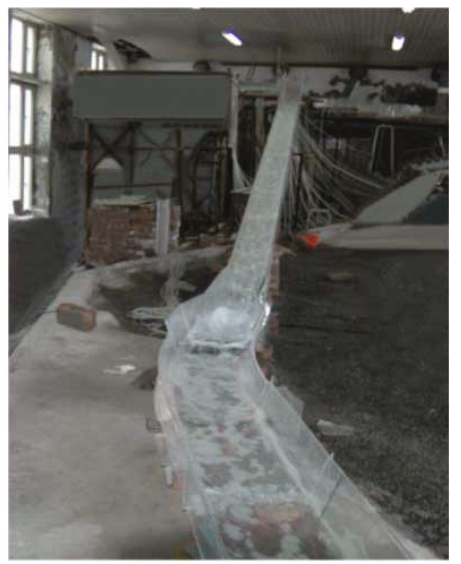

FIGURE 3: The full view of model in the laboratory.

viscous bottom layer. The flow field of the side channel spillway is calculated and simulated when the water level of the reservoir, respectively, arrives at design and collated flood level. Only the entrance section of the spillway is analyzed in the paper.

\section{The Results and Analysis}

5.1. The Outflow Capacity. To verify the accuracy of results, the outflow capacity of the WES side channel in the spillway is, respectively, shown in Table 2 according to numerical and experimental results; it can be found in Table 2 that numerical results are basically insistent with experimental ones; under the design flood level conditions, the magnitude of numerical results is higher $(4.17 \%)$ than one of the experimental results; under the collated flood level conditions, the magnitude of numerical results is higher $(1.43 \%)$ than one of the experimental results.

5.2. The Analysis of Flow State. The results of hydraulic model experiment demonstrate that under the design flood level conditions, the flow state of water ahead of the weir keeps steady, the fluctuation on the water surface is little, and the water flow over the weir is smooth; it is plotted in 


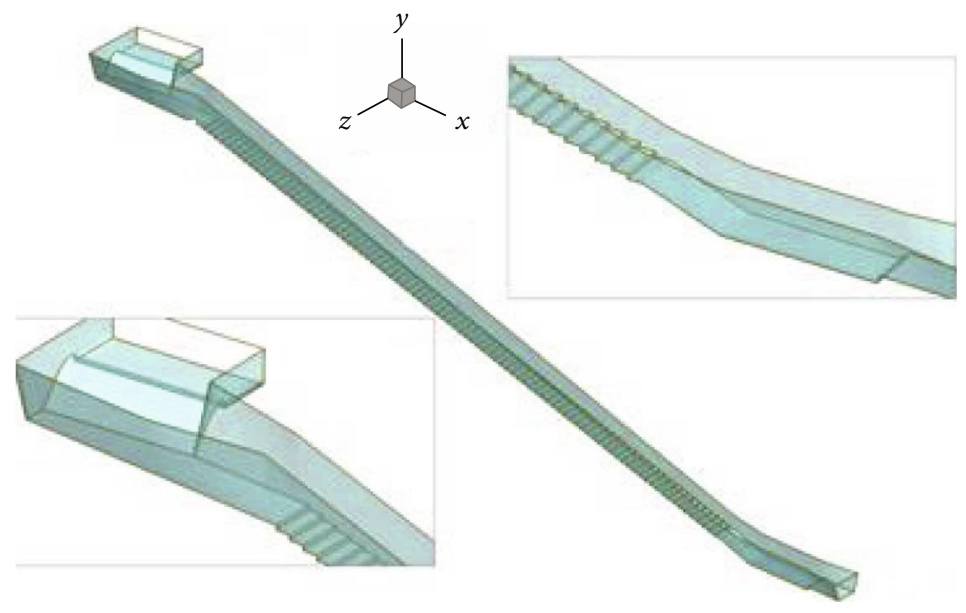

FIGURE 4: 3D model and boundary conditions.

TABle 2: The discharge capacity under different conditions.

\begin{tabular}{|c|c|c|c|c|c|}
\hline \multirow[b]{2}{*}{ Conditions } & \multicolumn{3}{|c|}{ Discharge rate $\left(\mathrm{m}^{3} / \mathrm{s}\right)$} & \multicolumn{2}{|c|}{ The relative error (\%) } \\
\hline & Design value & Numerical value & Experimental value & $\begin{array}{l}\text { The error between numerical } \\
\text { and design values }\end{array}$ & $\begin{array}{l}\text { The error between numerical } \\
\text { and experimental values }\end{array}$ \\
\hline Design flood level & 48.00 & 54.00 & 52.80 & 12.50 & 4.17 \\
\hline Collated flood level & 124.30 & 131.8 & 129.94 & 6.19 & 1.43 \\
\hline
\end{tabular}

Figure 5(a) photograph. When the water enters into the side weir section through the crest of the weir, because the intersection between the axial line of the spillway and weir is $99^{\circ}$, water flow is influenced by the side wall. The transverse circulation is generated in the side slot, and a water wall is formed at the right bank after the collision between the water flow and side wall. The water depth at the right bank is bigger than the one at the left bank at the same cross section, and the width and height of water flow increase as flow velocity increases. Under the collated flood level conditions (Figure 5(a) photograph), the flow on the surface of weir fluctuates because of big flow and the contractility of entrance before the weir. When water enters into side weir section, the spray is aroused from the mutual collision of transverse circulation. The fluctuation of water flow is rather violent; the height of the water wall at the right bank arrives at $6.38 \mathrm{~m}$. Its magnitude is less than the design height $8.73 \mathrm{~m}$ of the side wall.

The results of the numerical simulation model the flow state in the side slot accurately. Under the designed flood level conditions, it can be found in Figure 5(a) that after water enters into the side slot from the overflow weir, it submerged in the bottom, then rushes at the right side wall, and then rush into the water surface (blue lines represent the movement of air); because of the constraint of the right side wall, it returned to the left bank again, and obvious transverse circulation is formed after the air is involved into water. The maximum size of the whirlpools is the same as transverse dimensions in the side slot section. The fluctuation of water is violent; the water flow on the surface is mixed into the air. And it can be also found that the overflow in the side weir belongs to free overflow under the design flood level conditions. The water tongue in the side slot enters into the bottom of water, and the reverse spiral motion is generated when the water flow skims from the surface. Finally, the fluctuation of water surface is triggered. Then, water enters into the discharge tank section; it becomes stable gradually. Under the collated flood level conditions, it can be found from Figure 5(b) that water enters into the side slot from the overflow section; the flow state of water is similar to the one under the design flood level conditions; water circles round towards the left side after it arrived at the surface. It can also be found that under the collated flood level conditions, the water oscillates by a wide margin. The water level difference at the surface between the left and right side walls is rather big. In all, the numerical results of flow states in the side slot is consistent with the experimental ones.

5.3. The Distribution of Flow Velocity. The distribution of flow velocity in the cross section of the weir under the design and collated flood level conditions is, respectively, plotted in Figures 6(a) and 6(b). Under the design flood level conditions, the flow velocity arrives at the maximum at the upper of the curved face in the overflow weir, and the variation of flow velocity arrives at the maximum also. The fluctuation is violent. The water flow on the surface is mixed into the air, and rotational velocity occurs at the bottom of the side weir; the magnitude of flow velocity at the bottom is obviously less than one of the flow velocities on the surface. The water level at the front end of the side weir has the elevation at different extents; this kind of state is obvious, especially under the collated flood level conditions. The flow velocity at $7 \mathrm{~m}$ ahead of the weir, top of weir and cross section $0+000$, 

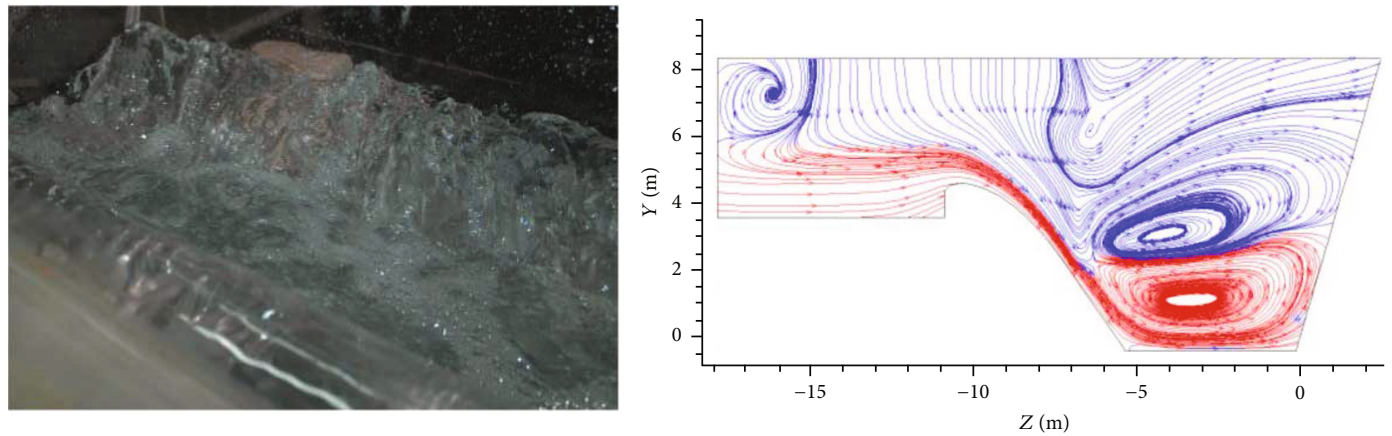

(a) Design flood level conditions
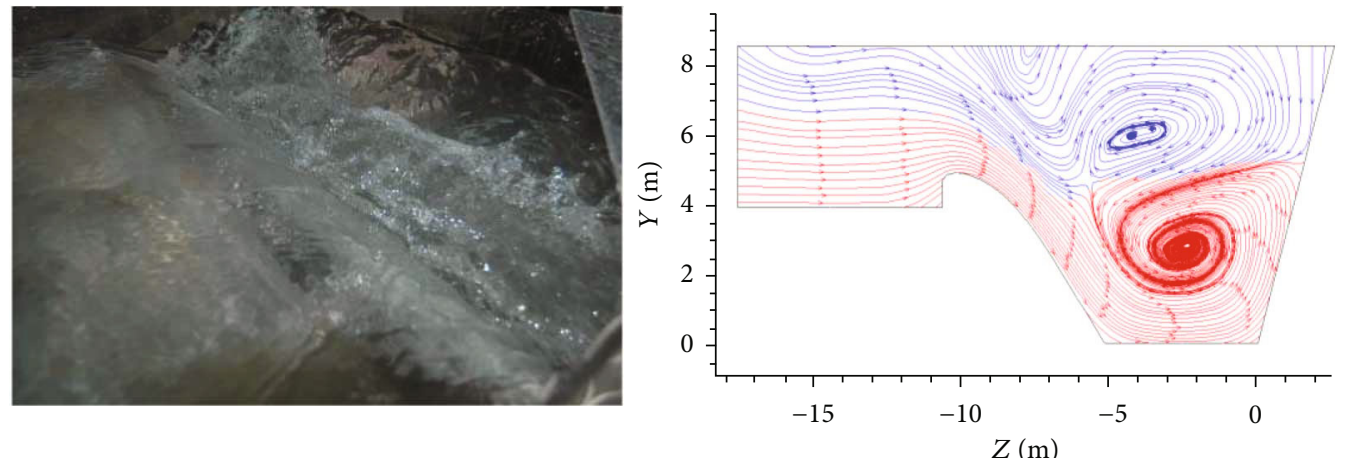

(b) Collated flood level conditions

Figure 5: The flow state of side channel.

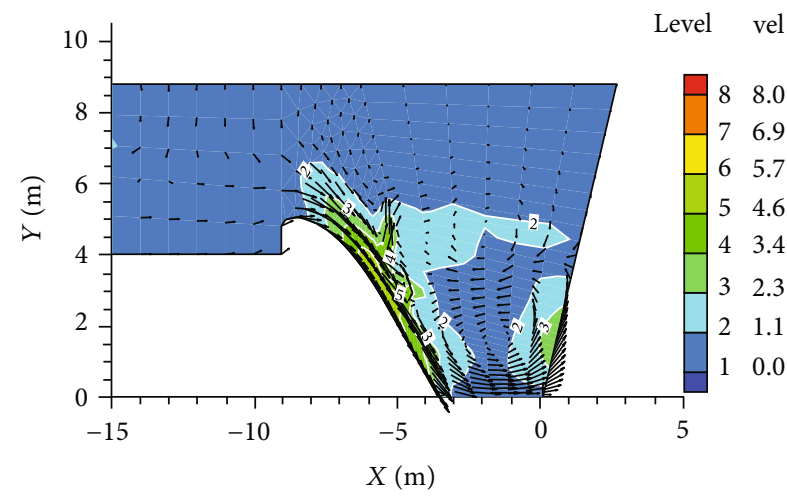

(a) The design flood level conditions

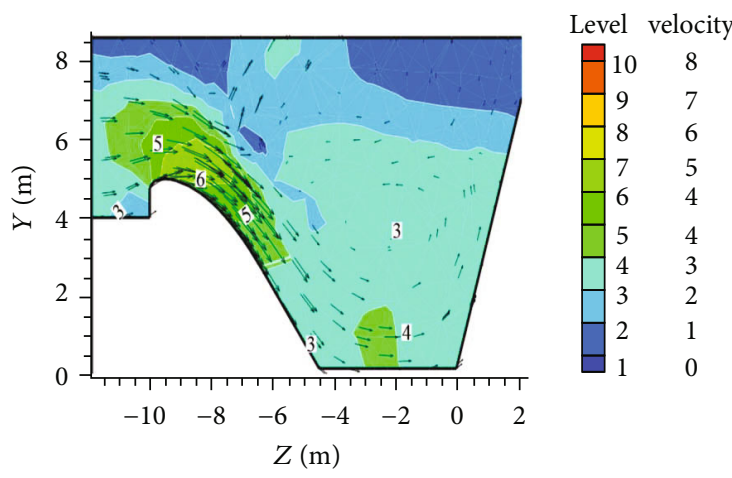

(b) The collated flood level conditions

Figure 6: The flow velocity distribution in the cross section of weir.

$0+007.5,0+015$ are respectively simulated; the results are shown in Table 3; it can be found in Table 3 that for the flow velocity of the weir top, under the design or collated flood level conditions, the errors between numerical and experimental magnitudes are, respectively, $3.0 \%$ and $7.11 \%$; the numerical results are basically consistent with experimental results.

5.4. The Water Surface Line. Under the design and collated flood level conditions, the comparisons of water depth between numerical solution and experimental value about the side slot, regulating section, the left or right side walls, and discharge tank section are, respectively, in Figures 7 and 8 ; the ordinate in the figure represents water depth, and the abscissa denotes the pile number of different cross sections. The velocity of discharge is big, the turbulent flow of water is violent, and the fluctuation of water is rather big in the experiment, so the maximum and minimum magnitudes of water depth at the right side wall at different classical cross sections are measured in the experiment (the water at the left or right side wall in the discharge tank section is the same in the experiment). It can be found that the calculative values of water depth at different classical cross sections are basically between the maximum and minimum values of water depth. The results of numerical simulation are basically consistent with the experimental results. Especially, the calculative magnitudes in the ladder-shaped 
TABLE 3: The velocity distribution at the entrance section.

\begin{tabular}{|c|c|c|c|c|c|c|}
\hline \multirow{2}{*}{ Pile number } & \multicolumn{3}{|c|}{ Design flood conditions } & \multicolumn{3}{|c|}{ Collated flood conditions } \\
\hline & Experimental value & Simulation value & Error & Experimental value & Simulation value & Error \\
\hline $7 \mathrm{~m}$ ahead of weir & 1.21 & 1.13 & 0.08 & 0.56 & 0.5 & 0.06 \\
\hline The top of weir & 5.48 & 5.32 & 0.16 & 5.22 & 5.62 & -0.4 \\
\hline $0+000$ & 2.02 & 2.10 & -0.08 & 0.45 & 0.39 & 0.06 \\
\hline $0+007.5$ & 2.59 & 2.66 & -0.07 & 1.12 & 1.05 & 0.07 \\
\hline $0+015$ & 4.02 & 3.92 & 0.10 & 1.82 & 1.91 & -0.09 \\
\hline
\end{tabular}

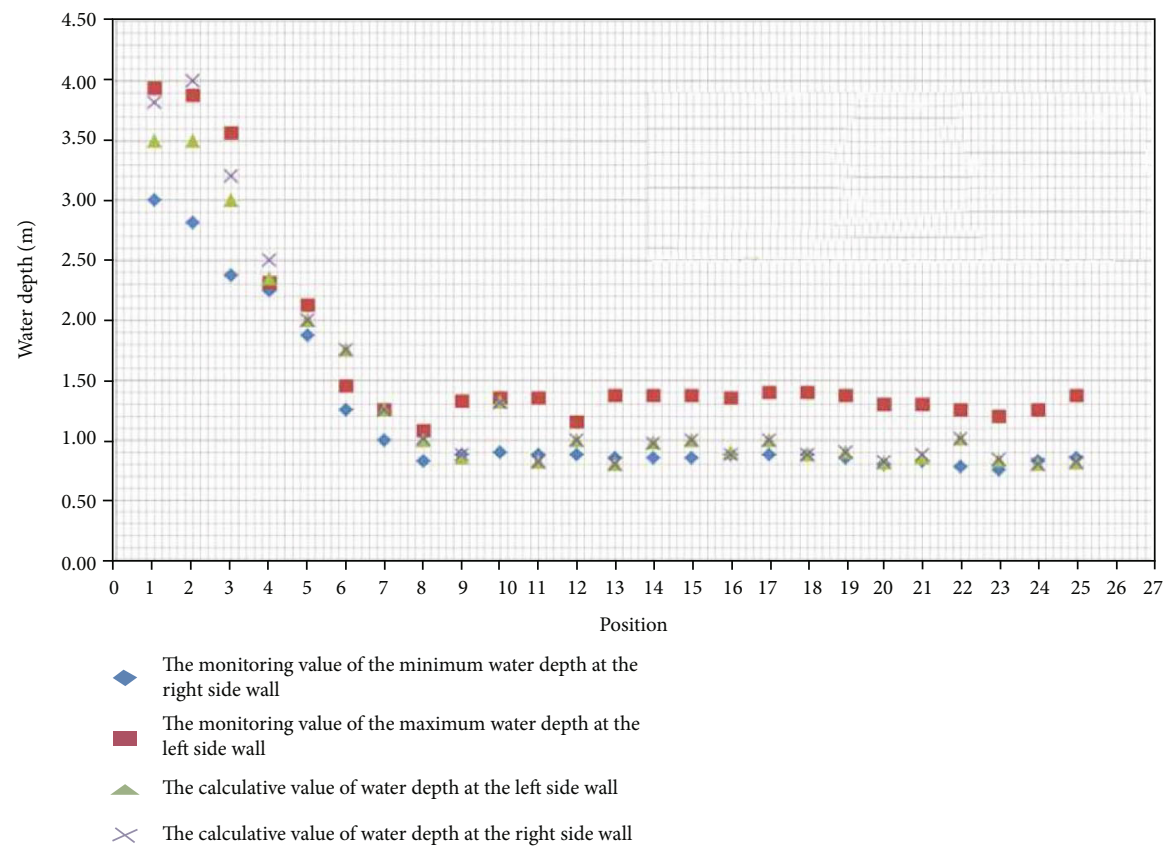

Figure 7: The comparison between numerical and experimental values of water depth at the side wall under the design flood level conditions.

discharge tank section coincide with the minimum magnitudes of water depth completely.

5.5. The Pressure. 96 monitoring points about the pressure are arranged along the path of the spillway; especially, 39 monitoring points are arranged in the side weir section. Their specific planar layout about the monitoring points is, respectively, in Figures 9 and 10.

According to relevant research [26], the calculation of pressure on the surface of the overflow weir is rather reliable by using Flow3D, so the numerical simulation is adopted to analyze the pressure of weir surface. The pressure distribution along the path in the spillway is plotted in Figure 11; the numerical results demonstrate that negative pressure does not occur in the WES weir in the control section of the spillway (Figure 11(a)). Under the design flood level conditions, the minimum magnitude of pressure at the bottom plane of the weir is about $0.45 \mathrm{kPa}$; the pressure in the reverse section increases greatly under the action of centrifugal force. The maximum magnitude happens at the end of arcuate segment, and its magnitude is about $38 \mathrm{kPa}$; the maximum pressure occurs at the front of the side slot section in the side tank and regulating sections; it can be found in
Figure 11(b) that under the collated flood level conditions, the pressure at the wall surface is about $0.6 \mathrm{kPa}$. The pressure in the reverse section increases greatly also because of the action of centrifugal force; the maximum value occurs at the end of the arcuate segment; it is about $60 \mathrm{kPa}$. The maximum pressure occurs at the front of the side slot section in the side weir and regulating sections; its magnitude is about $56 \mathrm{kPa}$.

5.6. The Energy Dissipation Rate. Under the slip flow conditions, for the ladder-shaped spillway, the energy dissipation of water is realized by the exchange between the split and aeration of water and turbulent motion of whirlpools at the mainstream and bottom. The dissipating efficiency of energy at the ladder section can be measured by using energy dissipation rate. The energy dissipation rate is defined as the ratio between the energy that is consumed from the top of the weir to the end ladder and total energy. Its formula can be depicted as follows:

$$
\eta=\frac{E_{1}-E_{2}}{E_{1}}
$$




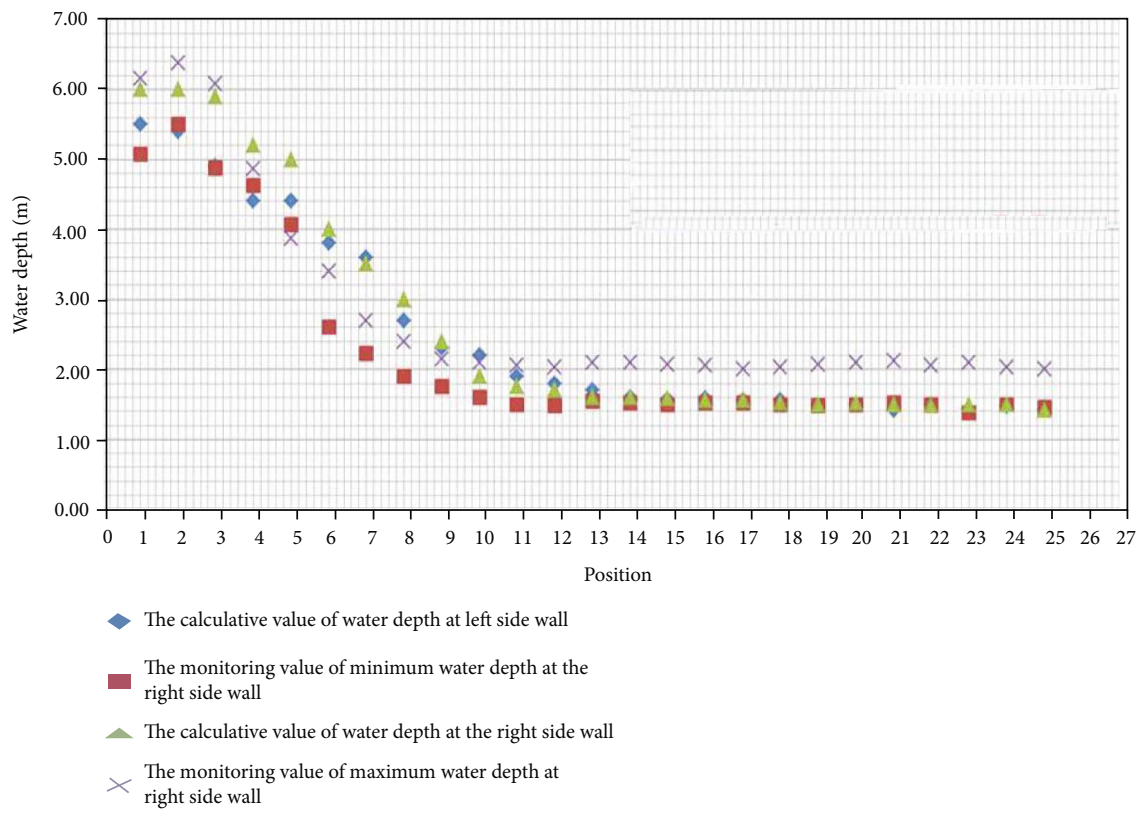

FIGURE 8: The comparison between numerical and experimental values of water depth at the side wall under the collated flood level conditions.

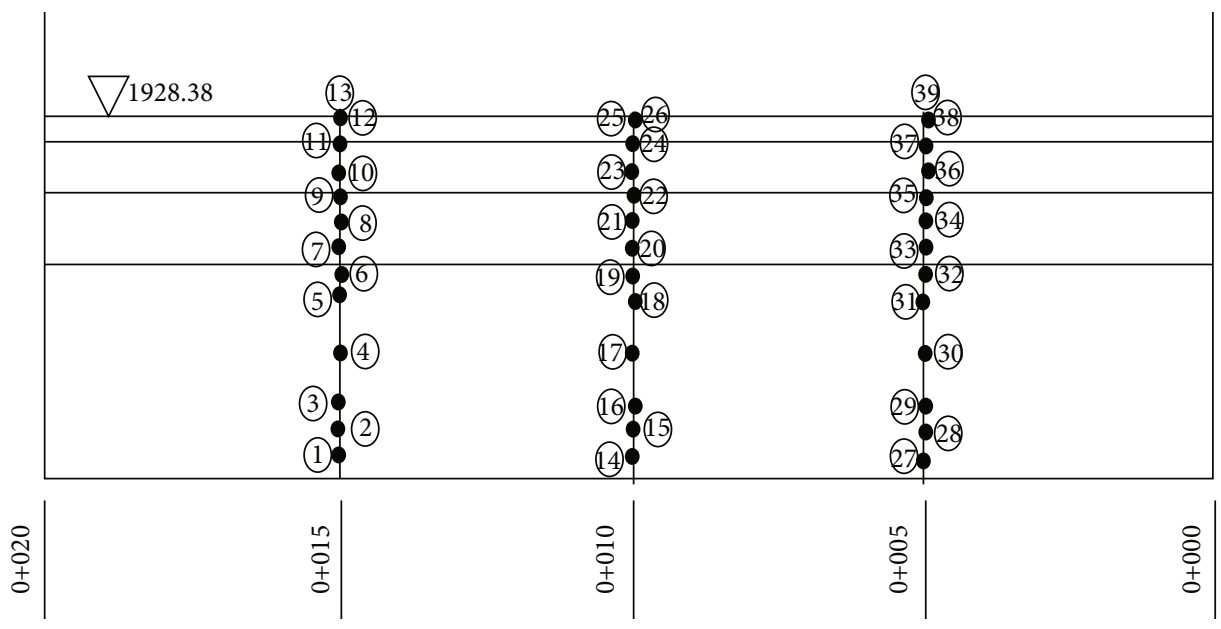

Figure 9: The planar layout of pressure pints.
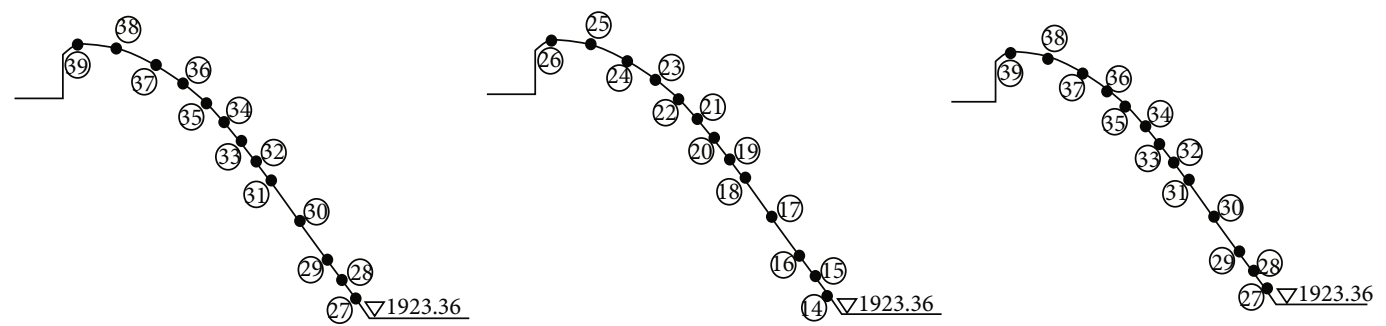

FIgURE 10: The longitudinal planar layout of pressure pints.

where $\eta$ is the energy dissipation rate; $E_{1}$ is the initial energy of water; and $E_{2}$ is the energy at the entrance cross section of stilling basin. The energy dissipation rate of the ladder-shaped spillway under two different conditions according to numerical simulation can be shown in Table 4. 


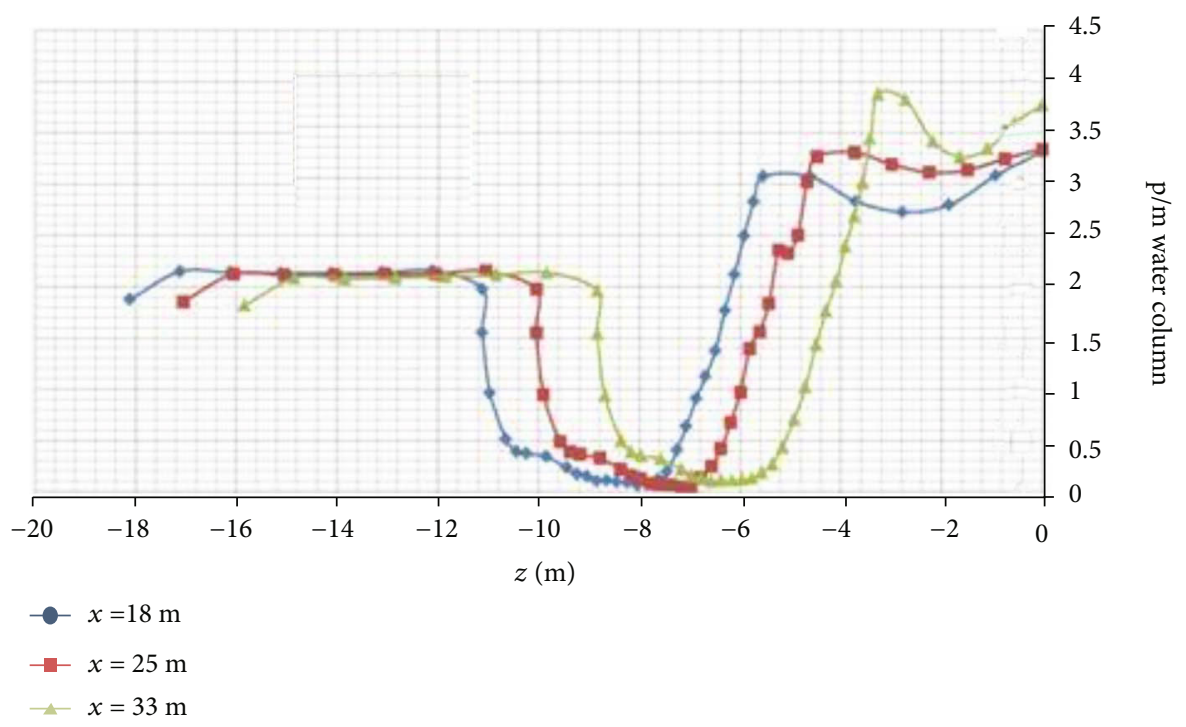

(a) The pressure distribution at the bottom plane of the WES weir under the design flood level conditions

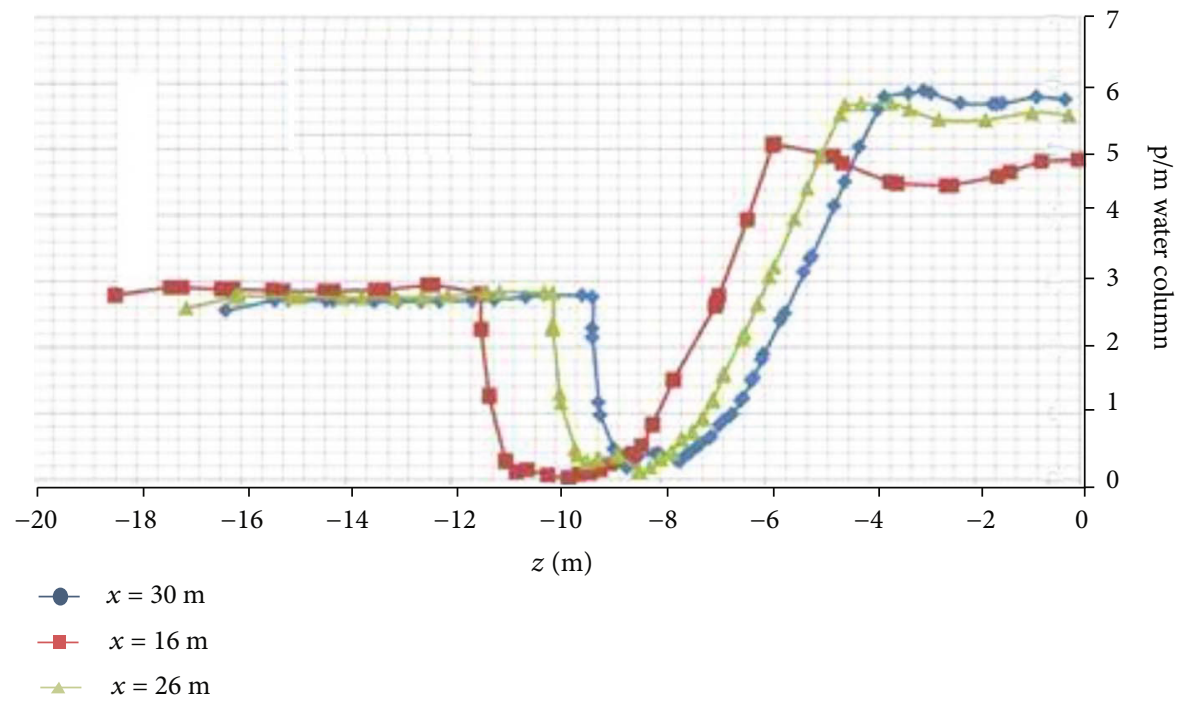

(b) The pressure distribution at the top plane of the WES weir under the collated flood level conditions

FIGURE 11: The pressure distribution in the WES weir.

TABLE 4: The energy dissipation rate of the spillway.

\begin{tabular}{lccc}
\hline Conditions & $\begin{array}{c}\text { Water } \\
\text { level }\end{array}$ & $\begin{array}{c}\text { Energy dissipation rate } \\
\text { Nesults }\end{array}$ & $\begin{array}{c}\text { Experimental } \\
\text { results }\end{array}$ \\
\hline $\begin{array}{l}\text { Design } \\
\text { conditions } \\
\begin{array}{l}\text { Collated } \\
\text { conditions }\end{array}\end{array}$ & $1929.02 \mathrm{~m}$ & 86.54 & 83.26 \\
\hline
\end{tabular}

The tumble of water is very violent. The aerating of water is obvious. The magnitude of energy dissipation rate calculated from the numerical simulation is $86.54 \%$ under the design flood level conditions. One in the experiment is $83.26 \%$; under the collated flood level conditions, the water level in the side slot is high; it belongs to the submerged overflow, so the efficiency of energy dissipation decreases. Under the collated flood level conditions, its energy dissipation rate in the numerical simulation is $78.15 \%$, and its experimental ones are $75.32 \%$.

\section{Conclusions}

The $3 \mathrm{D}$ numerical simulation is performed at the entrance section in the ladder-shaped spillway by using the relevant numerical software in the paper, and its results are compared with the experimental results; conclusions can be drawn as follows:

(1) The outflow capacity of the WES weir is shown in Table 1 according to numerical simulation; it can be found that numerical results are basically 
consistent with experimental results, and changeable law is the same

(2) The results of numerical simulation model the flow state in the side slot accurately; the numerical results of flow states in the side slot are consistent with the experimental ones; for the flow velocity of the weir top, under the design or collated flood level conditions, the errors between numerical and experimental value are, respectively, $3.0 \%$ and $7.11 \%$; the numerical results are basically consistent with experimental results; for the simulation of water surface line, the results of numerical simulation are basically consistent with the experimental results also; especially, the calculative magnitudes in the laddershaped discharge tank section coincide with the minimum magnitudes of water depth completely

(3) When the numerical simulation is adopted to calculate and analyze the pressure on the weir surface, the numerical results are consistent with the experimental results; negative pressure does not occur on the WES weir in the control section; the magnitude of energy dissipation rate obtained from the numerical simulation is $86.54 \%$ under the design flood level conditions; one in the experiment is $83.26 \%$; under the collated flood level conditions, its energy dissipation rate in the numerical simulation is $78.15 \%$, and its experimental ones are $75.32 \%$.

\section{Data Availability}

The data used to support the findings of this study are available from the corresponding author upon request.

\section{Conflicts of Interest}

The authors declare that they have no conflicts of interest.

\section{Acknowledgments}

This work is supported by the crossproject in Nanyang Institute of Technology (230067), National Natural Science Foundation of China (41672357), the Doctoral Start-up Foundation (510126), Science and Technology Support Program of Sichuan (No. 2020YJ0424), and Regional Innovation Cooperation Programs of Sichuan Province (2021YFQ0050).

\section{References}

[1] S. Zhang, C. Li, R. Liu, J. Bao, and M. Chi, "Effects of the variable valve lift difference on incylinder gas flow in a four-valve gasoline engine," Proceedings of the Institution of Mechanical Engineers, Part D: Journal of Automobile Engineering, vol. 233, no. 7, pp. 1806-1817, 2019.

[2] Z. Chen, H. Chen, L. Wang, L. Geng, and K. Zeng, "Parametric study on effects of excess air/fuel ratio, spark timing, and methanol injection timing on combustion characteristics and performance of natural gas/methanol dual-fuel engine at low loads," Energy Conversion and Management, vol. 210, article 112742, 2020.
[3] M. Dalla Nora, T. D. M. Lanzanova, and H. Zhao, "Effects of valve timing, valve lift and exhaust backpressure on performance and gas exchanging of a two-stroke GDI engine with overhead valves," Energy Conversion and Management, vol. 123, pp. 71-83, 2016.

[4] S. Kojima, S. Kiga, K. Moteki, E. Takahashi, and K. Matsuoka, "Development of a new 2L gasoline VC-turbo engine with the world's first variable compression ratio technology," SAE Technical Paper, 2018.

[5] Y. Zhao, C. L. Wang, L. Ning, H. F. Zhao, and J. Bi, "Pore and fracture development in coal under stress conditions based on nuclear magnetic resonance and fractal theory," Fuel, vol. 309, article 122112, 2022.

[6] K. Velusamy, P. Chellapandi, S. C. Chetal, and B. Raj, "Overview of pool hydraulic design of Indian prototype fast breeder reactor," Sadhana, vol. 35, no. 2, pp. 97-128, 2010.

[7] Q. Luo and B. Sun, "Experiments on the effect of engine speed, load, equivalence ratio, spark timing and coolant temperature on the energy balance of a turbocharged hydrogen engine," Energy Conversion and Management, vol. 162, pp. 1-12, 2018.

[8] T. Li, J. A. Caton, and T. J. Jacobs, "Energy distributions in a diesel engine using low heat rejection (LHR) concepts," Energy Conversion and Management, vol. 130, pp. 14-24, 2016.

[9] Y. Zhao, C. L. Wang, and J. Bi, “Analysis of fractured rock permeability evolution under unloading conditions by the model of elastoplastic contact between rough surfaces," Rock Mechanics and Rock Engineering, vol. 53, no. 12, pp. 57955808, 2020.

[10] B. Yan, H. Wang, Z. Zheng, Y. Qin, and M. Yao, "The effects of LIVC Miller cycle on the combustion characteristics and thermal efficiency in a stoichiometric operation natural gas engine with EGR," Applied Thermal Engineering, vol. 122, pp. 439450, 2017.

[11] Z. Zhang, R. Liu, G. Zhou et al., "Influence of varying altitudes on matching characteristics of the Twin-VGT system with a diesel engine and performance based on analysis of available exhaust energy," Proceedings of the Institution of Mechanical Engineers, Part D: Journal of Automobile Engineering, vol. 234, no. 7, 2020.

[12] K. Shen, Chang, H. Chen, Z. Zhang, B. Wang, and Y. Wang, "Experimental study on the effects of exhaust heat recovery system (EHRS) on vehicle fuel economy and emissions under cold start new European driving cycle (NEDC)," Manage, vol. 197, article 111893, 2019.

[13] D. L. Zhang, P. Song, S. Wang et al., "Analysis code development for the direct reactor auxiliary cooling system of the pooltype sodium-cooled fast reactor," Kerntechnik, vol. 83, no. 3, pp. 232-236, 2018.

[14] V. Knop and L. Mattioli, "An analysis of limits for part load efficiency improvement with VVA devices," Energy Conversion and Management, vol. 105, pp. 1006-1016, 2015.

[15] V. Grelet, T. Reiche, V. Lemort, M. Nadri, and P. Dufour, "Transient performance evaluation of waste heat recovery Rankine cycle based system for heavy duty trucks," Applied Energy, vol. 165, pp. 878-892, 2016.

[16] A. Khoshkonesh, B. Nsom, S. Gohari, and H. Banejad, "A comprehensive study on dam-break flow over dry and wet beds," Ocean Engineering, vol. 188, article 106279, 2019.

[17] E. S. Mohamed, "Development and analysis of a variable position thermostat for smart cooling system of a light duty diesel vehicles and engine emissions assessment during NEDC," Applied Thermal Engineering, vol. 99, pp. 358-372, 2016. 
[18] Y. Zhao, C. Wang, M. Teng, and J. Bi, "Observation on microstructure and shear behavior of mortar due to thermal shock," Cement and Concrete Composites, vol. 121, article 104106, 2021.

[19] Y. Zhao, Y. Zhang, H. Yang, Q. Liu, and G. Tian, "Experimental study on relationship between fracture propagation and pumping parameters under constant pressure injection conditions," Fuel, vol. 307, article 121789, 2022.

[20] J. Bi, P. F. Liu, and F. Gan, "Effects of the cooling treatment on the dynamic behavior of ordinary concrete exposed to high temperatures," Construction and Building Materials, vol. 248, article 118688, 2020.

[21] W. Fujun, Analysising of Computational Fluid DynamicsPrinciple and Application of CFD Software, Tsinghua University Press, Beijing, 2004, (in Chinese).

[22] Y. Zhao, J. Bi, C. Wang, and P. Liu, "Effect of unloading rate on the mechanical behavior and fracture characteristics of sandstones under complex triaxial stress conditions," Rock Mechanics and Rock Engineering, vol. 54, no. 9, pp. 48514866, 2021.

[23] P. Olmeda, J. Martín, F. J. Arnau, and S. Artham, “Analysis of the energy balance during world harmonized light vehicles test cycle in warmed and cold conditions using a virtual engine," International Journal of Engine Research, vol. 21, no. 6, pp. 1037-1054, 2020.

[24] G. Zhu, J. Liu, J. Fu, and S. Wang, "A combined organic Rankine cycle with double modes used for internal combustion engine waste heat recovery," Journal of Engineering for Gas Turbines and Power, vol. 139, no. 11, 2017.

[25] L. I. Jianbo and L. I. Li, "Three-dimensional numerical simulation on the hydraulic properties of the spillway of Zhangfeng reservior," Journal of Taiyuan University of Technology, vol. 46, no. 6, pp. 775-779, 2015.

[26] J. Yang, X. Dong, Q. Wu, and M. Xu, "Influence of flash boiling spray on the combustion characteristics of a spark- ignition direct-injection optical engine under cold start," Combustion and Flame, vol. 188, pp. 66-76, 2018. 